\title{
DOS DECIRES DE RECUESTA Y ALGUNAS NOTAS SOBRE POEMAS SUELTOS EN EL SIGLO XV
}

\author{
A Jaime Iglesias
}

En el momento en que redacto estas líneas ha transcurrido poco más de año y medio desde la aparición del Catálogo-Indice de la poesía cancioneril del siglo $X V$, obra monumental preparada por Brian Dutton ${ }^{1}$. Nada más caer en mis manos dicho trabajo, redacté una reseña para esta misma publicación ${ }^{2}$ en que, más que otra cosa, planteaba una serie de desiderata; la principal de ellas era mi confianza en que todos los hispano-medievalistas dedicados a estudiar la poesía de nuestros cancioneros contribuyesen con sus propias correcciones y nuevos datos a perfeccionar un trabajo sin lugar a dudas magnífico. Mejor que dar retazos sueltos o noticias separadas, supuse $-\mathrm{y}$ aún mantengo esta idea- que lo correcto sería que el propio Dutton centralizase todas las referencias y que él mismo ofreciese el nuevo material en una publicación periódica del tipo de La Corónica, siempre a la espera, claro está, de una inmediata segunda edición.

Las parcelas susceptibles de mayores variaciones son las propias del hallazgo y localización de nuevos cancioneros no incluidos en el primer censo ${ }^{3}$. Así, entre los datos distraídos se encuentran cancione-

\footnotetext{
1 Madison, Hispanic Seminary of Medieval Studies, 1982. Con la colaboración de Stephen Fleming y Jineen Krogstad (Archivos y Bibliografia), Francisco Sontoyo Vazouez (Programación), Joaouin Gonzalez Cuenca (Colaborador en España).

2 Revista de Filología Española, 64 (1984).

3 Habria sido necesario revisar para el caso de los impresos bibliografía más al día que la ofrecida por Francisco VINDEL, El arte tipografico en España durante LXV, $1 .^{\circ}-2.0^{\circ}-8$
} 
ros como el ms. 25-10-9 de la Biblioteca de Bartolomé March en Madrid, que contiene obras (Poemata es su título) de Fernán Pérez de Guzmán ${ }^{4}$, y algún que otro códice que, en la actualidad, han recogido especialistas participantes en este proyecto, ya en su segunda fase ${ }^{5}$. Sin embargo, existe una gran cantidad de material de difícil catalogación, aquél conservado a través de copias accidentales en los folios en blanco de cualquier códice o impreso medieval ${ }^{6}$.

Quienes tienen trato asiduo con manuscritos de nuestra Edad Media saben que, en numerosas ocasiones, estos recipientes se usaron para fines distintos de los que tenían en su origen. El empleo de los folios en blanco puede dirigirse a fines tan prácticos como puede ser anotar las cuentas de la casa o bien copiar algunas recetas médicas. Dentro del registro puramente literario hay material con especial disposición para aparecer en los folios y huecos en blanco de nuestros códices medieva-

el siglo $X V$, Madrid, 1945-51; así, no se hubieran producido casos como el del incunable 82 GM (GOMEZ MANRIQUe, Regimiento de príncipes, Zamora - Antonio de Centenera- ca. 1482), perdido según el Catálogo-Indice, del que F. R. GoFf, Incunabula in American Libraries (New York, 1964 [rep. 1973]), M-211, señala un ejemplar en la biblioteca Huntington de San Marino. Para impresos, vid. algunos ejemplos en n. 5.

4 Encuadernado en piel. Canto: «Fernando / Perez / de / Guzman / Poemata». Dentro, las antiguas signaturas: Phillipps 8288, Helcer 1297 (Nota: «Bretherton ligavit 1848). Papel y pergamino muy deteriorados, restaurados en algunos lugares. $1+166$ (verso) +74 (prosa) $+1.315 \times 220 \mathrm{~mm}$. (enc.), $300 \times 220 \mathrm{~mm}$. (fol.). Gótica libraria con rasgos cursivos del siglo xv. Filigrana similar a la núm. 689 de Briquet. Contiene: 1) [Falta primera página de tablas] Loores de los claros varones de España, ff. $2 \mathrm{r}-52 \mathrm{r}, 2)$ Confesión rimada, ff. 52v-76r. 3* Diuersas virtudes e viçios e hynnos rimados a loores diuinos enbiados al muy bueno e discreto Aluar Garçia de Sancta Maria, ff. 76v-156v. 4) Cuatro virtudes cardinales, ff. 157r-164v. 5) [Prosa] Oracional (incomp.), $64 \mathrm{ff}$. De este cancionero existía una referencia harto confusa en R. G. BLACK, "A Further Note on the Private Libraries of Spain», La corónica, 5 (1976), 36-37.

5 Proyecto del que soy colaborador $y$ al que han hecho importantes contribuciones algunos estudiosos españoles como Pedro $M$. Cátedra y Joaquín González Cuenca; además, participan especialistas de U.S.A., Reino Unido, Francia y Holanda.

6 El propio DutTon ha tenido ocasión de recoger algunas de estas referencias, como ocurre en el caso de su MN26. Cuando no se trata de copias sueltas en cancioneros, su fijación por escrito puede explicarse por una de estas tres razones: a) la escasez de papel y necesidad de consignar el poema, sea copia de otro códice, texto memorizado o nueva creación; b) la frecuencia de las probationes calami sive pennae; o c) un auténtico descanso en mitad de la tarea, como ocurre en el caso de aquel notario zaragozano, recordado por Manuel Alvar, que en 1416, wharto de copiar protocolos, incluye entre ellos el siguiente poema: $A y$, señora, ifasta cuando / andaré por vos penando? / ...», «Raíces de la literatura aragonesa», A. Egido, ed., La Literatura en Aragón (Zaragoza: Caja de Ahorros y Monte de Piedad de Zaragoza, Aragón y Rioja, 1984), págs. 15-32 [26-7]. Presente en DutTon, op. cit., n. 0138, como anónimo, debio de ser poema muy conocido, pues se encuentra como cita de Alponso ENRfougz en el Cancionero de Stúníiga y en el anónimo "Un día por mi ventura* de SA7, además de ser composición independiente en PN8 y PN12. 
les; me refiero, claro está, a los poemas cancioneriles, que se pueden insertar en el lugar que les es propio, un cancionero, llegando a copiarse incluso en impresos ${ }^{7}$. De este modo, podemos encontrarnos con copias diversas - tomadas de otro códice o citadas de memoria según la ocasión-, como pueden ser los Proverbios del Marqués de Santillana ${ }^{8}$, copiados en un manuscrito con obras de tipo moral. Frente a casos como el anterior, en que la obra copiada es de una calidad considerable, hay otros en que parece que nos hallamos tan sólo ante una prueba de que autores, copistas o lectores han tenido voluntad de hacer un pinito poético, aunque en algunos casos el arrepentimiento haya seguido a la primera intención ${ }^{9}$.

Interesantes sobremanera son los ejemplos de composiciones de cierta calidad que sólo hemos conservado en alguna ocasión más ${ }^{10}$; pero, por supuesto, los ejemplos más relevantes son aquellos en que este tipo de transmisión nos ofrece poemas de interés que constituyen el único testimonio conservado en manuscritos o impresos. Esto es lo que ocurre

7 Es lo que ocurre con las conocidas Inserciones iniciales del Cancionero de San Román (MH1); por lo que respecta a copias en impresos, una nueva referencia, que puede corresponder a un poema medieval -aunque es difícil delimitar las fronteras ante et post 1500 en poesía cancioneril-, es ese «El descanso es co(n)panero/.../quitaron vuestra venida», que aparece copiado con letra cortesana del siglo XVI según C. VALVERDE DEL BarRio en el incunable que lleva el número 158 de su Catálogo de incunables y libros raros de la Santa Iglesia Catedral de Segovia (Segovia, 1930), p. 95.

8 Ms. 8586 Bib. Nacional de Madrid (olim X-214). Papel, $78 \mathrm{ff} .217 \times 152 \mathrm{~mm}$. Letra cortesana del siglo xv. Contiene cinco obras en prosa. Los Proverbios (sólo se copian los tres primeros) se encuentran tras una obra de Juan Unay y la famosa carta de Rabí Samuel de Israel, fol. 78v.

9 Ms. 9132 Bib. Nacional de Madrid (olim Bb-103). Papel, 217 ff. $337 \times 260 \mathrm{~mm}$. Letra gótica cursiva del siglo xv, 2 cols. Entre un Valerio Máximo y Pro Marco Marcello de Cicerón se ha copiado un poema, tachado posteriormente, que reconstruyo: «[?]da es bien obrada / e muy graçiosa estola/mas vale que de seda labrada/pues que ella por sy sola / commo plata resplandeçiente/lengua clara de entender/non ya que reprehender/mas muy grand loor mereçe/Tela rezia tan conplida/non se puede texer ogaño/so ygual asy torçida/yo lo he por muy estraño/Nobles son sus materiales/a te vestir omne desnudo/porque tiene mucho rudo/esquiuo todos sus males/tengo que aquende de tajo/omne non podria fallar/por camino nin atajo/cosa en ella que omne dar/Pues a tantos sobrepuja/su filo primo torçido/non so yo tan atreuido/que en ella ponga aguja» (f. 214ra). Su autor tenía razones de sobra para arrepentirse de estos versos y tacharlos.

10 Así, junto a tres poemitas mas de menor talla, tenemos en el ms. 9256 de la Bib. Nacional de Madrid el poema «Quien beuir libre desea/no deve querer miraros / porque ninguno que os vea / no puede ser que no sea / cativo de desearos», copiado en el segundo folio en blanco de este códice, que contiene las Sumas de historia troyana de LeOMARTE. Este poema se conserva sólo en otros dos cancioneros, los mss. 617 y 1335 de la Bib. de Palacio. 
con los dos textos que ofrezco a continuación, modestas obras de recuesta que, sin embargo, guardan un gran encanto; ambos poemas están tomados del ms. 9268 de la Bib. Nacional de Madrid, que contiene dos obras de tipo historiográfico ${ }^{11}$ :

(fol. 107ra) Los de la Casa Real, señores todos e todas, fazetme para mis bodas mercedes en general. E algunos en (e)speçial muestren sus ledos senblantes: esto sea en los Infantes; que el Rey, que es todo él cabdal, luengos tienpos biua e goze, me fizo merçet de doze mill de moneda vsal. A la conclusión final, fallo por mi buena cuenta que me dio çiento e çinquenta doblas de oro con metal. E pues vos, la principal, alta Reyna de Castilla, muy fermosa a marauilla, resplandor angelical, non quiero que dedes al, sinon paños a la nouia, fechos a fuer de Segouia, enforrados en çendal. La más clara quel xristal, graçiosa gentil fadrina, linda infant(a) doña Catalina, esta estrella oriental, onrre en todas figuras con fermosas tocaduras a la nouia, o con brial.

(fol. 107rb) Don Juan, Infante leal,

11 Ms. 9268 (olim Bb-138). Papel, 155 ff. $270 \times 215 \mathrm{~mm}$. Letras gótica y cortesana del siglo xv. 2 cols. Los poemas se encuentran entre una Cronica abreuiada de los emperadores, reyes y consules de Roma y otra de los «Reyes que ouo desde el Rey don Pelayo fasta el Rey don Enrrique fijo del Rey don Iohan» (Crónica de los Reyes de Castilla, Sumario de los reyes de España). Ocupan f. 107ra-va.

Transcribo los textos con respeto de todas las grafías excepto $i$ y $j$ que empleo según el uso actual; sólo he eliminado la $r r$ en tres casos (ferrmosa, orrdenada, forrçada), pero la mantengo incluso tras $n$. Reconstruyo las abreviaturas en cursiva y cuatro vocales suprimidas por medio de paréntesis. Puntúo y acentúo según criterios modernos. 
sin desdén se'l glorifique con el alto infant(e) Enrrique, maestro que mucho val en el mundo, e cada qual den al nouio alguna ropa, sea balandrán o hopa o fruta pecunial. Finida

Que maguer material, mi poco saber non topa demandar taças nin copa, grand mula nin grand chiual.

Señora mía ensalçada, alta Reyna e poderosa, discreta e gentil señora de grand bondat arnesada, yo vos obe enbiada vna sinple petiçión, e non sé por qué entençión non fuestes della pagada. Es verdat que fue ordenada vn poquillo sospechosa porque yua generosa a los de la casa onrrada; pero fue cosa forçada fazer clara relaçión de ya quanta deboçión por el Rey a mí librada.

(fol. 107va) Agora Reyn(a), señora en todo el mundo e famosa, estrella marauillosa de linage aperatada, sea por vos perdonada la primera colación, mas la segunda leçión sea luego executada. Siquier por ser consolada con vuestra mercet mi esposa, Reyna misericordiosa sedle franca e mesurada con alguna ropa vsada de onesta guarniçión, sea de qualquier fayçión, non senzilla mas doblada. Finida 
Sy mi ventura menguada non mereçe tal raçión, bo con desesperaçión triste contra mi morada.

Difícil determinar quién escribió ambos poemas, aunque no cabe duda de que los mueve idéntico motivo y fueron redactados por un mismo poeta; podría ser uno de los personajes que pululaban por la corte de los Reyes Católicos, a cuya persona parece dedicar ambas composiciones ${ }^{12}$. Desde luego, nos enfrentamos a un poeta como Villasandino, de modesta extracción social. Por lo que respecta al diseño de estos dos poemitas, se ha empleado una variedad de la copla de arte menor para su composición: la primera es de rima múltiple, con dos versos -uno de engarce estrófico y otro interior- ausentes ( $1 \mathrm{~h} \mathrm{y} \mathrm{4d,} \mathrm{o} \mathrm{e,} \mathrm{según} \mathrm{se} \mathrm{considere);} \mathrm{así,} \mathrm{en} \mathrm{ambos} \mathrm{casos,} \mathrm{las} \mathrm{es-}$ trofas presentan siete versos. En el segundo poema hay un logrado empleo del sistema de tres rimas únicas, una de ellas (a) principal (como ocurre también en el poema 1). La asonancia de 2a frente al verso siguiente no respeta el esquema estrófico, ya que la rima debía ser en -ada.

Breves notas para dos pequeños poemas que, como otros muchos, formarán parte de los ingentes fondos reunidos por Brian Dutton y su equipo. Desde luego, la labor de localizar poemas sueltos necesitará mucho tiempo; para esta tarea es preciso que cada vez que se tropiece con material de tal condición se comunique la noticia a Dutton (Dept. of Spanish, Italien \& Portuguese, University of Illinois at Urbana-Champagne, Illinois 61801). Este breve trabajo no es sino una justificación para dejar caer este último ruego.

\section{Ángel Gómez Moreno}

Universidad Autónoma de Madrid

\footnotetext{
12 Es de suponer, si mi ojo no falla, que el autor de ambos poemas, por su estilo, el descaro al pedir y ese sospechoso interés por las ropas -que exhibe en otros poemas-, sea Antón de Montoro; si así fuese, el posesivo «mis bodas» correspondería a las nupcias de una de sus hijas, motivo que ya había merecido algún poema (núm. 97 de su Cancionero, ed. por Cantera y Carrete [Madrid, Editora Nacional, 1984], pág. 240). Ambos poemas podrían haber sido compuestos también con motivo de sus propias nupcias, en época de Juan II, en un momento de buenas relaciones con sus primos, los infantes de Aragón, el futuro Rey Juan II de Navarra, Enrique y su mujer, Catalina.
} 